\title{
Circumcision in Patients with Congenital Factor X Deficiency
}

\author{
Sinan Akbayram • Mesut Garipardic • \\ Kamuran Karaman • Salim Bilici • Ahmet Faik Oner
}

Received: 19 February 2014 / Accepted: 12 June 2014 / Published online: 29 June 2014

(C) Dr. K C Chaudhuri Foundation 2014

To the Editor: Congenital factor X deficiency (CFXD) is a rare inherited coagulation disorder, that has an incidence of 1 per million in the general population [1]. It usually presents with various hemorrhagic diathesis correlated with factor $\mathrm{X}$ levels [2].

There is no specific factor $\mathrm{X}$ replacement product readily available, but fresh-frozen plasma (FFP), prothrombin complex concentrates (PCC) and factor IX-X concentrate can be used for the treatment of bleeding symptoms and for surgery. Factor $\mathrm{X}$ coagulant activity of 15-30 IU/dL are thought to be hemostatic during surgery, but there is only limited information on the outcome and management of surgery in factor $\mathrm{X}$ deficiency [3].

The aim of this study was to evaluate our experience in circumcision of CFXD patients.

We retrospectively reviewed the medical records of three patients with CFXD who underwent circumcision at our hospital. These patients were 6,10 , and 15 y of age. Their diagnoses were severe (plasma factor X level <\%1) $(6$-y-old and 10 -y-old patients), moderate (plasma factor X level $\% 2$ ) (15-y-old patient). The laboratory examinations like complete blood count, serum electrolytes, liver, and renal function tests,

\footnotetext{
S. Akbayram $(\bowtie) \cdot$ M. Garipardic $\cdot$ A. F. Oner

Department of Pediatric Hematology, Yuzuncu Yil University,

65200 Van, Turkey

e-mail: drsinanakbayram@gmail.com

K. Karaman

Department of Pediatrics, Yuzuncu Yil Univeristy, Van, Turkey

S. Bilici

Department of Pediatric Surgery, Yuzuncu Yil University,

Van, Turkey
}

were found to be normal except prolonged prothrombin time (PT) and activated partial thromboplastin time (aPTT). The first dose of PCC at a dose of $500 \mathrm{IU}$ (10-15 IU/ $\mathrm{kg}$ of factor $\mathrm{X})$ was administered intravenously in all the three patients one hour before the operation. PT and aPTT values studied just before the circumcision operation were found to be within normal ranges. All the three patients received oral tranexamic acid $25 \mathrm{mg} / \mathrm{kg}$ three times a day for $1 \mathrm{wk}$, first dose was given $24 \mathrm{~h}$ after circumcision. Twenty-four hours after the circumcision, the patients were discharged. No thromboembolic or any other complications due to PCC administration have been found.

In summary, circumcision is a surgical and invasive procedure that needs to be done in hospital where an experienced surgeon and hematologist exist with sufficient access to adequate dosages of PCC and antifibrinolytic agents.

Conflict of Interest None.

Source of Funding None.

\section{References}

1. Peyvandi H, Duga S, Akhavan S, Mannucci PM. Rare coagulation deficiencies. Haemophilia. 2002;8:308-21.

2. Brown DL, Kouides PA. Diagnosis and treatment of inherited factor $X$ deficiency. Haemophilia. 2008;14:1176-82.

3. Auerswald G. Prophylaxis in rare coagulation disorders-factor X deficiency. Thromb Res. 2006;118:S29-31. 